\title{
SELENO-L-METHIONINE MODULATE THE TOXIC EFFECT OF NEW DOXORUBICIN METAL COMPLEXES IN PROKARYOTIC MODEL - ESCHERICHIA COLI RFM443 RECA::LUX
}

\author{
MARZENA MATEJCZYK*, GRZEGORZ ŚWIDERSKI \\ and WŁODZIMIERZ LEWANDOWSKI
}

Department of Chemistry, Biology and Biotechnology, Faculty of Civil Engineering and Environmental Engineering, Bialystok University of Technology, Białystok, Poland

\begin{abstract}
The main problem of modern cancer therapy is their resistance to the drugs used and the toxicity of drugs to healthy cells of the human body. Hope is natural substances that are protective of cells and often support the action of standard anticancer chemotherapy. Among them are selenium compounds. In the present study, we examined the cytotoxic and genotoxic potency of doxorubicin (DOX) metal complexes as new anticancer drug candidates. We also measured the effect of simultaneous administration of seleno -L-methionine as biologically active agent with DOX and its complexes with $\mathrm{Mn}, \mathrm{Mg}, \mathrm{Fe}$, Co and $\mathrm{Ni}$ in prokaryotic model Escherichia coli RFM443 with plasmid transcriptional fusion of recA promoter and luxCDABE as a reporter gene. The results obtained by us, indicate high biological activity of metal complexes with doxorubicin. The strongest modulatory effect was observed using the DOX complexes with Co and Ni compared to the DOX. The DOX complexes with Mg, Mn and Fe also showed relatively high biological activity. Simultaneous bacteria culture treatment with SeMet decreased the values of the DOX and its metal complexes cyto- and genotoxic parameters. These results encourage further research to assess the value of the doxorubicin metal complexes as new cytostatic drug candidates. While SeMet may be considered as therapeutic option in cancer treatment as modulation agent in anti-cancer therapy.
\end{abstract}

Keywords: cancer, selenium, DOX, metal complexes, toxicity

Abbreviations: DOX - doxorubicin, SeMet - seleno-L-methionine, MCF-7 - breast cancer cell line, GSH reduced glutathione, GPx - glutathione peroxidase, ROS - reactive oxygen species, TrxR - thioredoxin reductases, p53 - tumor suppressor protein, BRCA1 - human suppressor gene; breast cancer gene 1, Gadd45 - growth arrest and DNA damage gene, NAMI-A - imidazolium trans-DMSO-imidazole-tetrachlororuthenate complex

Nowadays, the increasing incidence of people suffering from cancer necessitates the development of new therapies and drugs that counteract these disease.

Selenium (Se) is an essential trace element for proper brain development and metabolic processes in vertebrates (1-2). Several studies presented that selenium acts as an antioxidant and can reduce the risk of cancer. Additionally, selenium participates in many important processes relevant to tumor biology such as immunity, fertility, cell growth, reactive oxygen species signaling, and tumor microenvironmental modulation (3-6). Recently, selenium has received considerable attention for its potential use in the prevention of cancer as a cytoprotective agent.
The underlying mechanisms of selenium cytoprotection potency against standard chemotherapeutic drugs are still not clear (1-6). Selenium (Se) is a metalloid in group VIA and an analog of sulfur, with four oxidation states in nature: selenate $(+6)$, selenite $(+4)$, elemental selenium $(0)$, and selenide $(-2)$. Se potency of oxidative stress regulation depends on the dose and its chemical forms (organic or inorganic selenium) (1-3).

Doxorubicin is an anticancer anthracycline antibiotic that has been successfully used in the treatment of a variety of neoplastic conditions, including leukemia, lymphoma and solid tumors. DOX works by intercalating with DNA and preventing its replication and transcription. Despite

\footnotetext{
* Corresponding author: e-mail: m.matejczyk@pb.edu.pl
} 
DOX is utilized for many years, it has been limited due to the significant toxicity that can occur not only during but also years after treatment (7-10). Serious side effects on the major organs including the heart, kidney and liver in the clinical application of DOX are main limitation. For these reasons, it is desirable to develop new variants of DOX with lower toxicity to healthy cells and with higher therapeutic efficacy (11-16).

Recently some authors showed the successful possibility of use of transition metal complexes as metal-based drugs to treat several human diseases like carcinomas, lymphomas, infection control, antiinflammatory, diabetes, and neurological disorders (16, 17-23).

Our team is involved with collaboration with the Medical University of Bialystok and MD Anderson Cancer Center (Houston, USA) in the implementation of the scientific project, entitled "Study on improving the selectivity and activity of selected drugs and natural compounds with anticancer properties due to metal complexation". Our preliminary studies showed a positive effect of a ligand with well documented cytostatic potency complexation with selected metals. During the metal complexation, molecular structure and distribution of electron charge were changed, resulting in differentiation of antitumor activity of tested chemicals. So far, we analyzed mainly natural compounds as quercetin, rosmarinic, caffeic, cinnamic and chlorogenic acids and known anticancer drugs doxorubicin and dacarbazine. Our results showed the cyto-, genotoxic and antimicrobial activity of some analyzed compounds (24-30). So, it suggests for possible application of them as potent anticancer and antimicrobial drug candidates. This subject demands further experiments.

The complexation of the anthracyclines by the metal ions led to discovery of the new, less toxic anticancer agents. Recently, obtained results by Jabłońska-Trypuć et al. (20) suggest that doxorubicin complexed by specified metals can be considered as a potential anti-breast cancer agent, which is characterized by a higher efficacy than a parent drug.

Bacterial genotoxicity bioassays with luminescent reporter genes have shown a high potential for the high-throughput screening in new drug and therapies development. Since the discovery of the legendary Ames test (1973 year), bacterial luminescence assays have become a very popular tool for determining the genotoxicity of environmental samples, chemicals and drugs (34-39). These bacterial assays apply genetically engineered microorganisms with plasmid transcriptional fusion of a genotoxinsensitive promoter with a gene or a group of genes the activity of which can be monitored quantitatively, preferably in real time. Such tests are a good, cheaper and faster alternative to animal testing. From an ethical standpoint, they are also less controversial. For genotoxicity assessment promoters which belong to the bacterial global DNA repair regulon (the SOS response) are selected (35-40).

The purpose of our experiment was to investigate the effects of metal complexation and SeMet on DOX and its new metal complexes: DOX-Mg, DOX-Mn, DOX-Fe, DOX-Co toxicity. In this biological assay, we used as a testing model Escherichia coli RMF443 strain which contained plasmid transcriptional fusion between genotoxin-inducible recA promoter from bacteria SOS regulon with luxCDABE gene as a reporter. Bacterial biosensors, detect the genotoxic mode of action of some chemicals and drugs, they are based on luminescence measurements. This leads to increase expression of lux $C D A B E$ gene and higher luminescence (35-40).

Recently, some authors have shown the positive effect of selenium with combination with cytostatic drugs (6-7, 10-11). There is no literature presented the examination of the effect of SeMet (seleno-L-methionine) and DOX and its new metal complexes using the recA::lux genetic system in $E$. coli. We wanted to answer the questions: "Do different concentrations of SeMet modulate the toxic effect of DOX and its metal complexes? and "Do DOX metal complexation change the toxic activity of DOX?"

In present work cytotoxic potency of tested chemicals were calculated on the basis of the bacteria growth inhibition values (GI). Genotoxic properties were calculated on the basis of the fold increase (FI) of SFI values normalized with control.

\section{EXPERIMENTAL}

\section{Chemicals preparation}

In our experiment, we used organic selenium in the form of pure seleno-L-methionine (SeMet) (Sigma Aldrich, UK). Synthesis of DOX complexes and its elemental analysis were described in our work Jabłońska-Trypuć et al. (20).

\section{Bacteria growth condition}

Escherichia coli RFM443 ( $\mathrm{F}^{-}$galK2 lac74 rpsL200) strains: Escherichia coli RFM443 recA: :luxCDABE (plasmid construct of recA::luxCDABE fusion is described by Yagur-Kroll et al. (37) and Yagur-Kroll and Belkin (38) and Escherichia coli 
DH5 $\alpha /$ pBR2TTS-pless were cultured overnight in $\mathrm{LB}$ agar medium (Merck, Germany) at $37^{\circ} \mathrm{C}$ supplemented with $100 \mu \mathrm{g} / \mathrm{mL}$ of ampicillin (SigmaAldrich, Germany). At the beginning of the experiment, the initial bacteria cells density was standardized to OD (Optical Density) value by using spectrophotometer $\left(\right.$ Glomax $^{\circledast}$, Multi Detection System, Promega) at the wavelength of $600 \mathrm{~nm}$. The concentration of bacteria cells per $\mathrm{mL}$ of $0.86 \% \mathrm{NaCl}$ was assessed by series dilutions system and expressed as CFU (colony forming units)/mL values. Dynamic growth of bacteria strains treated with chemicals was monitored by the use of standard spectrophotometer analysis of Optical Density values, at the wavelength of $600 \mathrm{~nm}$. The values of bacteria growth inhibition (GI) during the treatment (after 16 hours) with compounds used at the start of bacteria incubation was calculated according to the formula: $\mathrm{GI}(\%)=\mathrm{OD}_{\mathrm{CS}}(\%)-\mathrm{D}_{\mathrm{ODTS}}(\%)$, where: $\mathrm{OD}_{\mathrm{CS}}(\%)$ - Optical Density of control sample, = $100 \% ; \mathrm{D}_{\text {ODTS }}(\%)$ - the decrease in the value of Optical Density of bacteria samples treated with chemicals in relation to OD value of control sample.

\section{Analytical method for the intensity of lux biolu- minescence analysis}

Experimental conditions, luminescence measurement and data analysis were conducted according to the methods described by Yagur-Kroll et al. (37) and Yagur-Kroll and Belkin (38) with some modifications. To the assay, the bacterial strains were grown for $24 \mathrm{~h}$ at $37^{\circ} \mathrm{C}$ in $\mathrm{LB}$ broth supplemented with $100 \mu \mathrm{g} / \mathrm{mL}$ of ampicillin to $\mathrm{OD}_{600}=0.2$. The cells were then diluted 50-fold in fresh LB broth supplemented with ampicillin $(100 \mu \mathrm{g} / \mathrm{mL})$ and regrown with shaking at $37^{\circ} \mathrm{C}$. To the experiment, the bacterial strains which were grown for $20 \mathrm{~h}$ were taken. Seleno-L-methionine was simultaneously added to $1 \mathrm{~mL}$ of bacteria $\left(3 \times 10^{5} \mathrm{CFU} / \mathrm{mL}\right)$ treated with doxorubicin and its complexes with $\mathrm{Mn}, \mathrm{Mg}$, $\mathrm{Fe}, \mathrm{Co}$, and Ni. The final concentrations of selenoL-methionine were $62.5 \mu \mathrm{g} / \mathrm{mL}$, for doxorubicin and its complexes with $\mathrm{Mn}, \mathrm{Mg}, \mathrm{Fe}, \mathrm{Co}$, and $\mathrm{Ni}$ it was 5 $\mu \mathrm{M}$. After 16 hours exposition of bacteria cultures to the tested chemicals, the strains were washed with $0.86 \% \mathrm{NaCl}$ and the intensity of bioluminescence of lux gene in the volume of $100 \mu \mathrm{L}$ in the wells of opaque white 96-well microtitre plates was meas-

Table 1. RLU, Slux exp., FI, GI values for 16 hours treatment of E. coli recA::luxCDABE with DOX and its complexes with Mg, Mn, Fe, $\mathrm{Co}$ and $\mathrm{Ni}(5 \mu \mathrm{M})$ and incubated with SeMet $(62,5 \mu \mathrm{g} / \mathrm{mL})$ in comparison to the control sample.

\begin{tabular}{|c|c|c|c|c|}
\hline Samples & RLU \pm SD & $S_{\text {lux exp. }}$ & FI & $\mathrm{GI}(\%)$ \\
\hline DOX & $2771.17 \pm 99.70^{\mathrm{a}}$ & 753.14 & 7.53 & 10 \\
\hline DOX-Mg & $2513.05 \pm 117.26^{\mathrm{a}}$ & 683 & 6.83 & 7 \\
\hline DOX-Mn & $2451.01 \pm 81.78^{\mathrm{a}}$ & 666 & 6.66 & 7 \\
\hline DOX-Fe & $2519.94 \pm 90.24^{\mathrm{a}}$ & 684.86 & 6.85 & 7 \\
\hline DOX-Co & $2641.36 \pm 43.93^{\mathrm{a}}$ & 718 & 7.18 & 9 \\
\hline DOX-Ni & $2634.31 \pm 60.68^{\mathrm{a}}$ & 716 & 7.16 & 12 \\
\hline DOX-SeMet & $759.29 \pm 46.27^{\text {bcdefg }}$ & 206 & 2.06 & 8 \\
\hline DOX-Mn-SeMet & $1272.44 \pm 27.66^{\text {abcdefg }}$ & 346 & 3.46 & 5 \\
\hline DOX-Mg-SeMet & $1124.13 \pm 23.73^{\text {abcdefg }}$ & 305 & 3.05 & 6 \\
\hline DOX-Fe-SeMet & $1429.53 \pm 263.52^{\text {bcdefg }}$ & 388 & 3.88 & 6 \\
\hline DOX-Co-SeMet & $1331.07 \pm 25.22^{\text {abcdefg }}$ & 362 & 3.62 & 5 \\
\hline $\operatorname{rec} A: \because \operatorname{lux} C D A B E-\mathrm{SeMet}$ & $1684.31 \pm 37.75^{\text {abcdefg }}$ & 457.75 & 4.58 & 2 \\
\hline Control - recA::luxCDABE- & $367.95 \pm 29.21$ & - & - & - \\
\hline $\begin{array}{l}\text { recA::luxCDABE-MNNG } \\
\text { (positive control) }(80 \mu \mathrm{M})\end{array}$ & $3164.4 \pm 92.30$ & & 8.6 & 16 \\
\hline $\begin{array}{c}\text { Promoter-less: } \\
\text { DH5 } \alpha / \text { pBR2TTS-pless }\end{array}$ & $6.15 \pm 0.98$ & - & - & - \\
\hline
\end{tabular}

Mean values $\pm \mathrm{SD} ; \mathrm{n}=8$; a - significantly different from control $(\mathrm{p}<0.05)$; $\mathrm{b}$ - significantly different from DOX group ( $<<0.05)$; - significantly different from DOX-Mg group $(\mathrm{p}<0.05)$; $\mathrm{d}$ - significantly different from DOX-Mn group $(\mathrm{p}<0.05)$; e - significantly different from DOX-Fe group $(\mathrm{p}<0.05)$; f- significantly different from DOX-Co group $(\mathrm{p}<0.05)$; $\mathrm{g}$ - significantly different from DOX-Ni group $(\mathrm{p}<0.05)$. 
ured using Glomax ${ }^{\circledast}$ (Multi Detection System, Promega) luminometer. Experiments were conducted in three independent series. The concentration range of the analyzed chemicals and the time of bacteria incubation with chemicals $(16 \mathrm{~h})$ were selected experimentally from the minimum level of recA::luxCDABE construct sensitivity and according to the reviewed references recommendation (2225). The control sample - Escherichia coli RFM443 recA: :luxCDABE strain in $0.86 \% \mathrm{NaCl}$ was not treated with chemicals. For verification, the correct activity of recA promoter, Escherichia coli $\mathrm{DH} 5 \alpha /$ pBR2TTS-promoterless strain without the promoter was used as the negative control of genetic construct.

\section{Assessment of RLU values}

Luminescence values are reported as the relative luminescence units (RLU) and are defined as culture luminescence intensity (IL) divided by optical density (OD) at $600 \mathrm{~nm}$ for cell culture. RLU value was calculated according to the below formula for monitoring the dynamic of lux expression after bacteria treatment with chemicals: RLU $=$ IL/OD where: RLU - Relative Luminescence Intensity, IL - The raw luminescence intensity of the strains, OD - Optical Density at $600 \mathrm{~nm}$ of the strains.
The percentage stimulation of lux expression $\left(\mathrm{S}_{\text {luxesp. }}\right)$ value.

The percentage stimulation of lux $\left(\mathrm{S}_{\text {luxexp. }}\right)$ was calculated according to the formula:

$\mathrm{S}_{\text {luxexp. }}(\%)=\mathrm{I}_{\mathrm{TS}}(\%)-\mathrm{RLU}_{\mathrm{CS}}(\%)$; where $\mathrm{I}_{\mathrm{TS}}(\%)-$ the increase of RLU values for tested compounds as a response to the level of lux expression in comparison with the control sample, $\mathrm{RLU}_{\mathrm{CS}}(\%)-\mathrm{RLU}$ for the control sample, $=100 \%$.

\section{The fold increase values calculations}

The dose-response data was expressed as fold increase (FI) of RLU value normalized with control and calculated according to the formula: $\mathrm{FI}=$ $\mathrm{RLU}_{\mathrm{TS}} / \mathrm{RLU}_{\mathrm{CS}}$; where: FI - fold increase of RLU values; $R_{\mathrm{TL}}$ - RLU values of tested sample; $R_{\mathrm{CS}}-\mathrm{RLU}$ values of control sample.

\section{Results presentation}

The results are presented (Table 1, Figs. 1 and 2) either as the difference in the intensity of the RLU values in the absence and presence of the inducer (tested chemicals) or as the percent of the lux gene stimulation/inhibition to that of the non-induced control $\left(\mathrm{S}_{\text {luxexp. }}, \mathrm{I}_{\text {luxexp. }}\right)$ or as the ratio of the luminescence of the induced sample to that of the noninduced control (fold induction-FI) as described by previously authors (37-38).

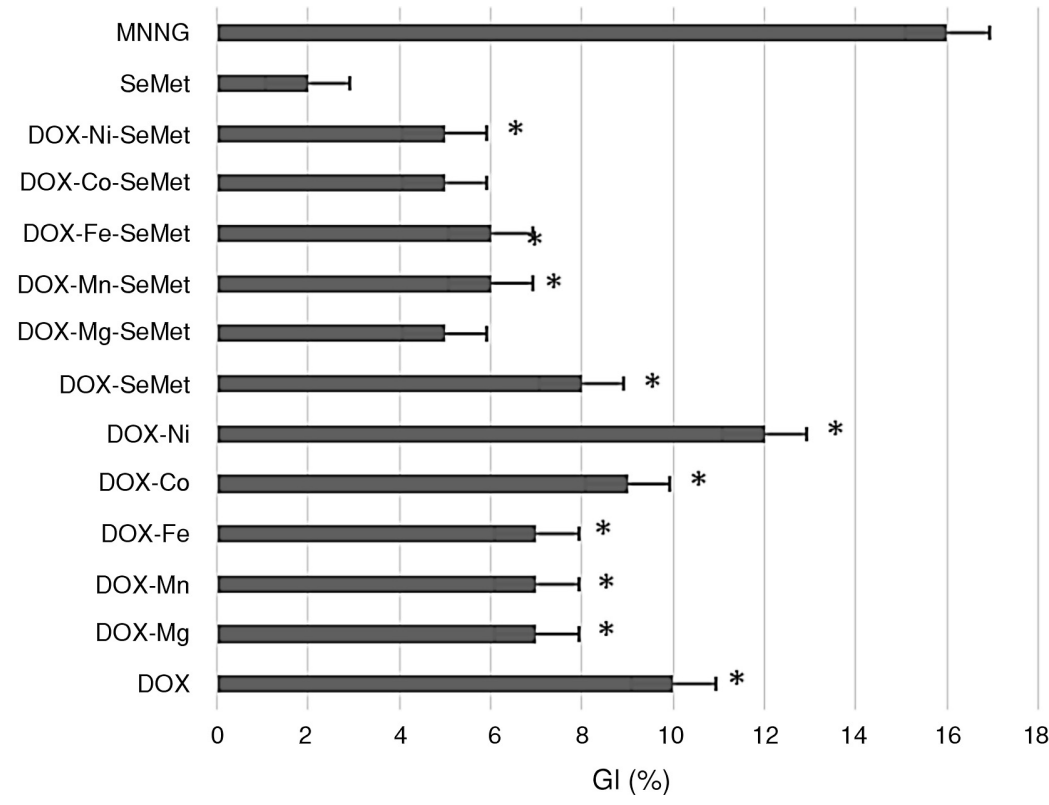

Figure 1. The percent of growth inhibition (GI\%) values for 16 hours treatment of E. coli recA: $:$ luxCDABE with DOX and its complexes with $\mathrm{Mg}, \mathrm{Mn}, \mathrm{Fe}$, Co and $\mathrm{Ni}(5 \mu \mathrm{M})$ and incubated with SeMet $(62.5 \mu \mathrm{g} / \mathrm{mL})$ in comparison to the control sample. ${ }^{*}-$ significantly different from control $(\mathrm{p}<0.05)$; Mean values $\pm \mathrm{SD} ; \mathrm{n}=8$ 


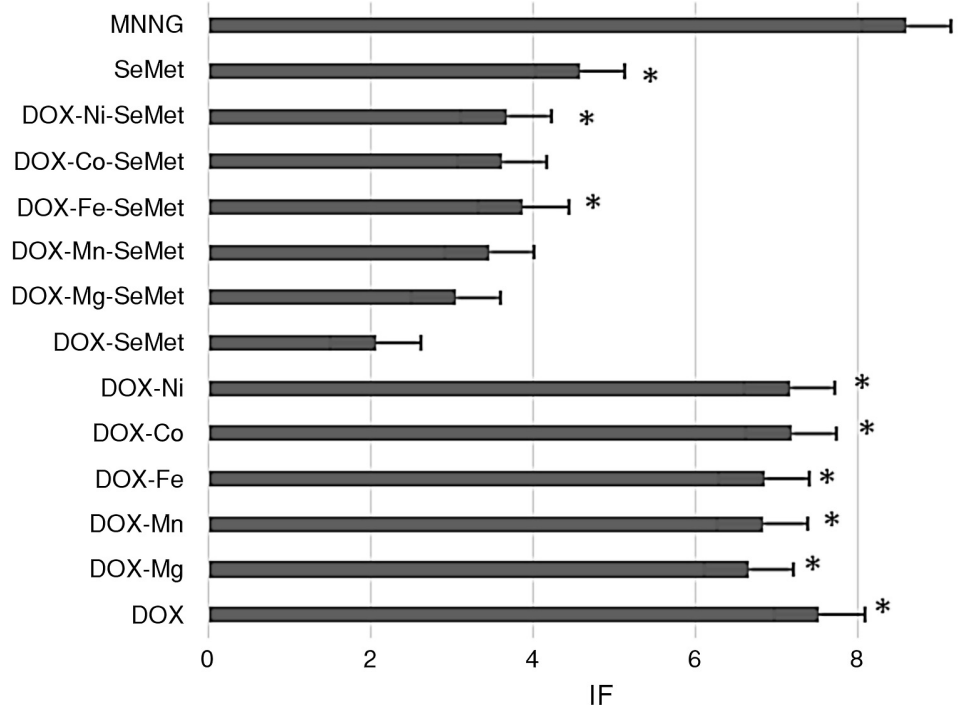

Figure 2. The fold induction (FI) of SFI value normalized with control for 16 hours treatment of $E$. coli recA::luxCDABE with DOX and its complexes with $\mathrm{Mg}, \mathrm{Mn}, \mathrm{Fe}$, Co and $\mathrm{Ni}(5 \mu \mathrm{M})$ and incubated with SeMet $(62.5 \mu \mathrm{g} / \mathrm{mL})$. $^{*}$ - significantly different from control $(\mathrm{p}<$ $0.05)$; Mean values $\pm \mathrm{SD} ; \mathrm{n}=8$

\section{Statistical analysis}

Data obtained from eight measurements $(n=8)$ are expressed as a mean \pm standard deviation (SD). Results were analyzed using standard statistical analyses, including one-way Student`s test for multiple comparisons. p-values less than 0.05 were considered significant.

\section{RESULTS}

The cytotoxic potency of tested compounds was calculated on the basis of optical density (OD) measurements of treated bacteria culture and expressed as percent of growth inhibition (GI) values (Fig. 1). To define the elasticity of recA : luxCDABE genetic construct in E. coli, it was exposed to a known very potent genotoxin as positive control - 1-Methyl-3-nitro-1-nitrosoguanidine (MNNG) at a concentration of $80 \mu \mathrm{M}$. Among the analyzed chemicals MNNG proved to be the strongest inhibitor of bacterial growth with GI = $16 \%$ in comparison to the control sample. In the remaining cases of tested compounds, the highest cytotoxic potential was found for the DOX-Ni complex $(\mathrm{GI}=12 \%)$, DOX $(\mathrm{GI}=10 \%)$, DOX-Co complex $(\mathrm{GI}=9 \%)$ and DOX-SeMet. The lowest values of inhibition of bacterial growth were recorded for SeMet with GI $=2 \%$.
The genotoxic activity of analyzed chemicals measured on the basis of dynamic of RLU values revealed the highest lux gene expression stimulation by MNNG (FI = 8.6), DOX (FI = 7.53), DOX-Co (FI = 7.18), DOX-Ni (FI = 7.16), DOX-Fe (FI = 6.85), DOX-Mg $(\mathrm{FI}=6.83)$ and DOX-Mn $(\mathrm{FI}=6.66)$. The smallest genotoxic activity toward to recA::luxCDABE genetic construct in $E$. coli was demonstrated by DOXSeMet $(\mathrm{FI}=2.06)$, DOX-Mg-SeMet $(\mathrm{FI}=3.05)$, DOX-Co-SeMet $(\mathrm{FI}=3.62)$, DOX-Ni-SeMet $(\mathrm{FI}=$ 3.67), DOX-Mn-SeMet (FI = 3.46) (Table 1, Fig. 2).

Following the recommendation of earlier authors $(31-32,34)$, concerning the validation of sensitivity of assessment of recA::luxCDABE genetic biosensing system in $E$. coli, $4 \%$ acetone was tested as the negative control. In the case of this chemical, there was no increase in FI values for $16 \mathrm{~h}$ of incubation. Methylnitronitrosoguanidine (MNNG) known genotoxin at the concentration of $80 \mu \mathrm{M}-$ was used as the positive control. For this analyte FI $=8.6$ was obtained. These results proved higher sensitivity of a $E$. coli recA::luxCDABE system for MNNG than for an acetone stressor.

\section{DISCUSSION}

Recently, due to the scientifically documented benefits of selenium, it has become the subject of 
research into its potential use in anticancer therapy. In this experiment, the influence of simultaneous administration of SeMet, DOX and its $\mathrm{Mg}, \mathrm{Mn}, \mathrm{Fe}$, $\mathrm{Co}$ and $\mathrm{Ni}$ complexes on $E$. coli with genetic fusion of genotoxin-sensitive recA promoter and luxCDABNE reporter gene was measured. Cyto- and genotoxic activity parameters for these compounds were analyzed. In our results, we indicated the highest cytostatic potency for DOX-Ni, DOX-Co complexes, and DOX. Similar results were presented in the work of Jabłońska-Trypuć et al. (20) where authors showed the most significant decreases in $\mathrm{MCF}-7$ cancer cells proliferation in case of $\mathrm{Mg}$ DOX, Mn-DOX and Ni-DOX at $0.5 \mu \mathrm{M}$ concentration after $24 \mathrm{~h}$ treatment. The potential of free radical generation is the most frequently described mechanism of cytotoxicity of various forms of selenium. However, studies of recent years indicate that Se induces cytotoxicity not only through ROS generation but also by affecting corresponding genes and proteins (1-6).

For inorganic medicinal chemistry, 1960 year became a groundbreaking year due to the discovery of strong antitumor properties of cisplatin and its derivatives. Unfortunately, the long-term treatment with these drugs leads to drug-resistance and nonspecific toxicity, especially healthy cells. It is the main stimulation factor for the development of alternative transition metal-based anti-tumor therapeutic agents. In recent years, several interesting and promising works have been published in the world literature on new variants of metal complexes as potential oncological drugs. Hartinger et al. (38) and Leijen et al. (39) presented two ruthenium derivates, imidazolium trans-DMSO-imidazole-tetrachlororuthenate (NAMI-A) (complex 1) and imidazolium trans[tetra-chlorobis(1H-indazole)-ruthenate(III)] (KP1019) (complex 2) as anti-metastatic and anti-neoplastic chemicals that have been tested in clinical trials. While, other transition metal-based complexes with anti-tumor activities include redox-mediating mono (thiosemicarbazone) copper complexes (3839), the gold (I) complex auranofin, which acts via inhibiting DNA, RNA and protein synthesis, and osmium(II) arene complexes that target mitochondria and induce cell apoptosis (21, 38-39). For more details we recommend very interesting review work of Liang at all. (21) where authors presented recent years discoveries of transition metal-based complexes that have shown in vivo anti-tumor activities. Also, complexation of DOX with copper (II) and iron (II) has been the main topic of Feng et al. (19) work and other authors $(13-16,18)$ Literature data show an increase in cytotoxic effect after DOX metal complexation compared to parent drug (DOX). In addition, metal complexes $\mathrm{Mn}^{2+}, \mathrm{Fe}^{2+}$ and $\mathrm{Cu}^{2+}$ with doxorubicin stimulate the accumulation of drug in liposomes, facilitate the binding of DOX to DNA and they increase the generation of reactive oxygen species (ROS) and enhance their cytotoxic effect. Probably ROS generation is the main molecular mechanisms responsible for increasing the cytotoxic effect of metal complexes relative to parent drug (13-16, 18-21). Our studies also point to the increased cytotoxicity of doxorubicin complexes with nickel and cobalt as compared to DOX. In addition, we showed that also $\mathrm{Mg}, \mathrm{Mn}$, and Fe complexes with DOX presented quite high biological activity compared to parental DOX. It is known, that metals play a very important structural or catalytic functions in living cells. On the other hand, high metal concentrations are often toxic. Metals have very favorable binding properties with other important cellular components and their deactivation. They disrupt enzyme functions and structures by binding with thiol and other groups in proteins. Co can inactivate Fe-S proteins, interfere with sulfur metabolism and $\mathrm{Fe}-\mathrm{S}$ cluster biogenesis, and cause the formation of reactive oxygen species. While, Ni can replace $\mathrm{Fe}$ in many enzymes or bind to cysteine, histidine or negatively charged residues in active sites of non-metal enzymes $(16,19,21)$.

In our experiment, we found out that simultaneous treatment of bacteria exposed to DOX and its metal complexes with SeMet significantly differentiate the cyto- and genotoxicity of the parent drug and its metal complexes. The biological activity of chemical forms of selenium has been investigated by different authors. It was shown, that selenium has chemopreventive and anticancer action. Everything depends on the form of selenium (organic or inorganic) and its dose used. Selenium, depending on the dose used, has antioxidant or prooxidant properties and it is also called "two faced compound" (13 ). Regarding the chemopreventive activity, a mechanism usually exerted by different selenocompounds is the glutathione peroxidase-like activity. Among the inorganic selenocompounds, selenite can be highlighted by its chemopreventive and anticancer action. On the other hand, the mechanisms of action of the organic selenocompounds are very diverse. Some of the most frequent is the reduction of oxidative stress through the elimination of free radicals. Moreover, selenocompounds can act through other less usual mechanisms, such as the inhibition of angiogenesis, the inhibition of the efflux pumps in cancer multidrug resistant cell lines and the enhancement of the activity of chemothera- 
peutic drugs. The chemical structure of anticancer and chemopreventive organic selenocompounds also shows a great variety, including selenocyanates, selenoureas, selenoesters, heterocycles with endocyclic selenium, selenium nanoparticles, selenides and diselenides (1-6).

In our experiment, we presented that, organic form of selenium - SeMet has a biological effect on DOX and its metal complexes cyto- and genotoxic activity. In the obtained results, we also noticed a statistically significant effect of SeMet on the level of lux gene expression in E. coli. Our results suggest, that SeMet protected bacteria cells against oxidative stress generation by DOX and its metal complexes. Moreover, Se molecular mechanisms of action are correlated with its influence on gene expression. Watson et al. (5) examined the protective effect of Se supplementation on cellular metabolism during oxidative stress. They supplemented trophoblast cells with organic and inorganic forms of Se and 3 forms of peroxide in a range of doses to generate oxidative stress. These studies confirmed, that selenium supplement up-regulates endogenous antioxidant system and protects trophoblast cells from oxidative stress. Additionally, it was proved, that selenium compounds prevent DNA damage by increasing the activity of repair enzymes such as DNA glycosylases and DNA damage repair pathway that involve p53, BRCA1, growth arrest and DNA damage gene (Gadd45) (6). Selenium as a trace antioxidant element plays a very important role in the function of selenoproteins, enzymes that are essential for protection against oxidative damage, such as glutathione peroxidase (GPx) and the regulation of immune function. In 2008 Tripathi and Jena (41) showed that selenium attenuated the cyclophosphamide (CP)-induced oxidative stress, toxic effect and DNA damage in mice. Similar conclusions have also been reached by Bhattacharjee et al. (42) where authors described protective ability of nano-Se against hepatotoxicity and genotoxicity induced by $\mathrm{CP}$. The toxicity effects reduction by $\mathrm{Se}$ compounds were obtained also in the case of cisplatin and temozolomide (1-3, 41-42). Our findings also point to the modulation properties of SeMet against the cyto- and genotoxic effects of doxorubicin and its metal complexes in E. coli. The main, underlying molecular mechanisms of anticancer activity of selenium remained unknown (2-4). In addition, as shown by the results of research from recent years, selenium, depending on the chemical form (organic or inorganic) and the dose used, may act as an antioxidant or prooxidant. Recent experiments with the use of cultured cells, animal models as well as human clinical studies indicate that one possible mechanism by which selenium supplementation may exert its benefits is by enhancing the DNA damage repair response. Se supplementation reduced the frequency of DNA adducts and chromosome breaks, consequentially reducing the likelihood of detrimental mutations that ultimately contribute to carcinogenesis. Moreover, Se is a critical constituent of selenoproteins such as glutathione peroxidases (GPx) and thioredoxin reductases (TrxR), proteins that play important roles in antioxidant defense $(1-6,41)$.

\section{CONCLUSIONS}

Our experiment indicated that DOX metal complexation create new biologically active compounds with potent cytotoxic and genotoxic ability. Metal ions ( $\mathrm{Mg}, \mathrm{Mn}, \mathrm{Fe}, \mathrm{Co}$, and Ni modulate the biological activity of DOX. The highest biological activity was observed with the use of Co and Ni. Moreover, applied metal complexes with DOX expressed strong influence on lux gene expression.

In this work, SeMet was used for the investigation of its influence on cyto- and genotoxic activity of DOX and its new metal complexes. SeMet showed great biological activity and its differentiate the cyto- and genotoxic activity of DOX and its metal complexes. Our results suggest, that doxorubicin metal complexes could be potent new cytostatic drug candidates. While SeMet, because of its very attractive biological properties, could be potentially useful in anticancer therapy as modulation agent.

\section{Acknowledgements}

Authors are very grateful to Prof. Shimshon Belkin, Dr. Tal Elad, and Dr. Sharon Yagur-Kroll, Institute of Life Sciences, The Hebrew University of Jerusalem, Jerusalem, Israel for providing bacteria strains, references recommendation and great scientific help.

\section{Funding}

This work was financially supported by the National Science Centre, Poland, under the research project number 2014/13/B/NZ7/02352.

\section{Disclosure of interest}

The authors report no conflicts of interest. 


\section{REFERENCES}

1. Lipiński B.: Med. Chem. Ant. Canc. Agents 17, 658 (2017).

2. Kieliszek M., Lipiński B., Błażejak S.: Cells 6, 39 (2017).

3. Kieliszek M., Lipiński B.: Med. Hypothes. 110, 15 (2018).

4. Álvarez-Pérez M., Ali W., Mar’c M.A., Handzlik J., Domínguez-Álvarez E.: Molecules 23, 628 (2018).

5. Watson W., Van Leer L., Vanderlelie J.J., Perkins A.V.: Placenta 33, 1012 (2012).

6. Bera S., De Rosa V., Rachidi W., Diamond A.M.: Mutagenesis 28, 127 (2013).

7. Yakubov E., Buchfelder M., Eyüpoglu I.Y., Savaskan N.E.: Biol. Trace Elem. Res. 161, 246 (2014).

8. Brozmanova J., Manikova D., Vlckova V., Chovanec M.: Arch. Toxicol. 84, 919 (2010).

9. Lü J., Zhang J., Jiang Ch., Deng Y., Özten N., Bosland M.C.: Nutr. Cancer 68, 1 (2016).

10. Safinaz I.S., Barakat M.A., Helmy H.M.: Life Sci. J. 7, 162 (2010).

11. Sheng Y., Liu G., Wang M., Lv Z., Du P.A.: Int. J. Biol. Macromol. 104, 393 (2017).

12. Abushouk A.I., Ismail A., Salem A.M., Afifi A.M., Abdel-Daim M.M.: Biomed. Pharmacother. 90, 935 (2017).

13. Turner N., Biganzoli L., Di L.A.: Lancet Oncol. 7, 362 (2015).

14. Mitry M.A., Edwards J.G.: IJC Heart Vasc. 10, 17 (2016).

15. Banerjee B., Koketsu M.: Coord. Chem. Rev. 339, 104 (2017).

16. Misra S., Boylan M., Selvam A., Spallholz J.E., Björnstedt M.: Nutrients 7, 3536 (2016).

17. Pang Y., An B., Lou L., Zhang J., Yan J. et al.: J. Med. Chem. 60, 7300 (2017).

18. Domracheva I., Kanepe-Lapsa I., Jackevica L., Vasiljeva J., Arsenyan P.: Life Sci. 186, 92 (2017).

19. Pilco-Ferreto N., Calaf G.M.: Int. J. Oncol. 49, 753 (2016).

20. Jabłońska-Trypuć A., Świderski G., Krętowski R., Lewandowski W.: Molecules 22, 1106 (2017).

21. Ma D.L., Liu L.J., Leung K.H., Chen Y.T., Zhong H.J. et al.: Angew. Chem. Int. Ed. 53, 9178 (2014).

22. Leung C-H., Liu L-J., Leung K.-H., Ma D-L.: Coord. Chem. Rev. 319, 25 (2016).
23. Liang J.-X., Zhong H.-J., Yang G., Vellaisamy K., Mab D.-L., Leun Ch.-L.: J. Inorg. Biochem. 177, 276 (2017).

24. Matejczyk M., Kalinowska M., Świderski G., Lewandowski W., Rosochacki S.J.: Acta Pol. Pharm. 73, 1139 (2016).

25. Matejczyk M., Świsłocka, R., Golonko A., Lewandowski W., Hawrylik E.: Adv. Med. Sci. 63, 14 (2017).

26. Matejczyk M., Świsłocka R., Kalinowska M., Świderski G., Lewandowski W. et al: Acta Pol. Pharm. 74, 801 (2017).

27. Matejczyk M., Świsłocka R., Kalinowska M., Świderski G., Lewandowski W., JabłońskaTrypuć A.: Acta Pol. Pharm. 74, 809 (2017).

28. Świsłocka R., Piekut J., Lewandowski W.: Spectrochim. Acta Part A 100, 31 (2013).

29. Świsłocka R.: Spectrochim. Acta Part A 37, 21 (2013).

30. Kowczyk-Sadowy M., Świsłocka R., Lewandowska H., Piekut J., Lewandowski W. Molecules 20, 3146 (2015).

31. Domínguez-Álvarez E., Gajdács M., Spengler G., Palop J.A. et al.: Bioorg. Med. Chem. Lett. 26, 2821 (2016).

32. Li W., Guo M., Liu, Y., Mu W., Deng G. et al.: Biol. Trace Elem. Res. 171, 371 (2016).

33. Gajdács M., Spengler G., Sanmartín C., Marc M.A., Handzlik J., Domínguez-Álvarez E.: Med. Chem. Lett. 27, 797 (2017).

34. Sakalli Çetin E., Nazıroglu M., Çig B., Övey 'I.S., Aslan Kosar P.J.: Recept. Signal. Transduct. Res. 37, 84 (2017).

35. Hassan S.H.A., Van Ginkel S.W., Hussein M.A.M.: Environ. Int. 92, 106 (2016).

36. Van Der Meer J.R., Belkin S.: Nat. Rev. Microbiol. 8, 511 (2010).

37. Yagur-Kroll S., Bilic B., Belkin S.: Microb. Biotechnol. 3, 300 (2010).

38. Yagur-Kroll S., Belkin S.: Anal. Bioanal. Chem. 400, 1071 (2011).

39. Melamed S., Lalush Ch., Elad T., Yagur-Krol S., Belkin S., Pedahzur R.: Microb. Biotechnol. 5, 536 (2012).

40. Leijen S., van Geel R.M., Pavlick A.C., Tibes R., Rosen L. et al.: J. Clin. Oncol. 20, 4371 (2016).

41. Tripathi D.N., Jena G.B.: Free Radic. Res. 42, 966 (2008).

42. Bhattacharjee A., Basu A., Ghosh P., Biswas J., Bhattacharya S.: J. Biomater. Appl. 29, 303 (2014).

Received: 14.12.2017 